\title{
Burocratizar para não Corromper: o impacto de atores transnacionais nas medidas anticorrupção da estratégia nacional de combate à corrupção e à lavagem de dinheiro ${ }^{1}$
}

\author{
Burocratize not to Corrupt: the impact of transnational actors on the anti- \\ corruption measures of the national strategy to combat corruption and \\ money laundering
}

\author{
Márcio Ricardo Staffen ${ }^{1}$ \\ ${ }^{1}$ Faculdade Meridional, Passo Fundo, RS, Brasil
}

\begin{abstract}
Resumo: A pesquisa que se apresenta tem como objetivo analisar o impacto de atores transnacionais nas alterações da burocracia estatal brasileira anticorrupção por meio das diretrizes exaradas pela Estratégia Nacional de Combate à Corrupção e à Lavagem de Dinheiro (ENCCLA). A apreciação sobre as ações da ENCCLA, no período compreendido de 2010 até 2020 , sinaliza o impacto dos atores transnacionais na burocratização dos instrumentos nacionais anticorrupção, destacando uma mutação na racionalidade administrativa e influenciando comportamentos executivos, legislativos e judiciais de prevenção e de combate à corrupção. Utilizou-se, para o desenvolvimento da presente pesquisa, o método indutivo.
\end{abstract}

Palavras-chave: Burocracia. Corrupção. Atores Transnacionais. ENCCLA.

\begin{abstract}
The research that is presented aims to analyze the impact of transnational actors in the alterations of the Brazilian anticorruption state bureaucracy through the guidelines established by the National Strategy to Combat Corruption and Money Laundering (ENCCLA). The assessment of the actions of the ENCCLA, in the period from 2010 to 2020 , signals the impact of transnational actors in the bureaucratization of national anticorruption instruments, highlighting a mutation in rationality administrative and influencing executive, legislative and judicial behaviors to prevent and combat corruption. For the development of this research, the inductive method was used.
\end{abstract}

Keywords: Bureaucracy. Corruption. Transnational Actors. ENCCLA.

${ }^{1}$ Texto decorrente de estudos pós-doutorais com bolsa da Coordenação deAperfeiçoamento de Pessoal de Nível Superior (CAPES/PDE).

Recebido em: 16/04/2019

Revisado em: 29/06/2020

Aprovado em: 09/07/2020 


\section{Introdução}

Após uma sequência de investigações, denúncias e condenações, cíveis, penais e administrativas, por inúmeros casos de corrupção, a sociedade brasileira a elegeu (a corrupção) como a principal fonte de receio e preocupação social, superando temores antigos como o desemprego, a violência e o acesso aos direitos sociais. Em que pese a dificuldade semântica de circunscrição e de tipificação dos atos rotulados como corrupção, para $73 \%$ dos brasileiros entrevistados pela CNI-Ibope, há associação entre atos de corrupção e a burocracia administrativa pública (OLIVON, 2018). Resultado similar obteve a Câmara de Comércio Estados Unidos-Brasil (AmCham), quando registrou que 75\% dos entrevistados culpa o excesso de burocracia pela corrupção sistêmica brasileira (CULTURA..., 2019).

No âmbito transnacional, seguindo os indicadores eleitos pela Transparência Internacional, o Brasil, mesmo com mudanças políticas, investigações criminais organizadas e controle pela opinião pública, piorou seus resultados sobre Índice de Percepção da Corrupção (IPC) (TRANSPARÊNCIA..., 2019). Desde o início da atual metodologia, inaugurada em 2012, o Brasil chegou ao seu pior resultado em 2018, somando apenas 35 pontos de um total de 100 pontos, ficando na $105^{\circ}$ posição no ranking mundial, estando empatado com Egito, Peru, Costa do Marfim, Zâmbia, Timor Leste e Argélia. Em 2019, o Brasil, mesmo com mudanças políticas substanciais, arrefecimento de novos casos de corrupção no âmbito da alcunhada Operação Lava-Jato ${ }^{2}$ e com pequena retomada econômica, conservou apenas 35 pontos no Índice de Percepção da Corrupção (IPC) (TRANSPARÊNCIA..., 2019).

Escândalos no decurso dos últimos anos, desde 2014, ocasionaram o impeachment da Presidente da República, prisão de outros dois ex-Presidentes da República, condenação de Governadores de Estados, detenção

\footnotetext{
${ }^{2}$ Iniciada em 2014, trata-se da mais destacada operação de investigação, persecução e julgamento criminal de condutas relacionadas com corrupção, lavagem de dinheiro e organização criminosa que usava de contratos administrativos com empresas públicas para fins de desvio de recursos públicos e utilização em financiamento de políticos e partidos políticos com ramificações em mais de 20 países e quatro continentes.
} 
de Ministros, afastamento de Deputados e Senadores, prisão de Reitor de Universidade Federal, pedido de investigação contra Ministros da Corte Constitucional e do Ministério Público Federal. Empresários antes indexados nas listas Forbes foram detidos, fizeram acordos de colaboração premiada e ocasionaram o fechamento da Bolsa de Valores de São Paulo (BOVESPA). Conglomerados industriais nacionais de liderança global restaram responsabilizados por comportamentos ilegais, desde o processamento de proteína animal até a mineração. Todos esses episódios, conexos ou não, além de potencializar a percepção de corrupção na vida social brasileira, produziram o sistemático descrédito de instituições relevantes e o clamor por purificação. Simultaneamente, em nível global, tornou-se constante o combate à corrupção como tópico de relevo em cenários transnacionais (BRATSIS, 2017, p. 23).

Nesse sentido, a presente pesquisa objetiva analisar, no intervalo temporal entre 2010 e 2020, as ações produzidas pela Estratégia Nacional de Combate à Corrupção e Lavagem de Dinheiro (ENCCLA), primeiro sobre o foco das medidas de burocratização associadas com o combate à corrupção e, noutro lado, a relação dessas medidas com influências de atores transnacionais e mecanismos de governança transnacionais.

Justifica-se a pesquisa em vias de relato pelas circunstâncias políticas, institucionais e Jurídicas recentemente experimentadas no Brasil, especialmente pela importância de se compreender os atos originários de inovações na regulamentação de determinadas condutas, até então isentas de interferências estatais e, de outro lado, pela inegável elevação do combate à corrupção como pauta global de reivindicações e mobilizações jurídicas.

Acrescente-se ao quadro em tela a sobrevivência do senso comum, segundo o qual a causa principal da corrupção sistêmica vigente no Brasil está atrelada com o excesso de burocracia estatal, que impõe exigências legais demasiadas para, posteriormente, oferecer troca de favores e facilidades proporcionalmente remuneradas e agraciadas por comodidades.

Nesse sentido, o norte traçado no Brasil para o combate à corrupção e à lavagem de dinheiro, principalmente no seio da Estratégia Nacional de Combate à Corrupção e à Lavagem de Dinheiro (ENCCLA), desafia 
uma condição paradoxal, pois de um lado instrumentaliza maior burocratização para minimizar casos de corrupção, quando justamente, para a maioria da população e dos políticos, a burocracia é a raiz da cultura de corrupção.

No que diz respeito à metodologia, utilizou-se para o desenvolvimento da presente pesquisa do método indutivo, por meio da técnica de conceitos operacionais e da pesquisa bibliográfica, bem como, análise de relatórios oficiais e de indicadores transnacionais.

\section{Notas sobre a Relação Burocracia e Corrupção no Brasil}

A pioneira presença da coroa portuguesa serviu de condição para imposição de forma idêntica de Estado. Uma forma particular de Estado, tipicamente lusitana. Nos dizeres de Raymundo Faoro, o poder do Estado português institucionaliza-se por meio de um tipo central de domínio: o patrimonialismo, produto direto da tradição da metrópole, ou seja, assim é porque sempre foi. O patrimonialismo estatal, ao apoiar a especulação econômica, movido pelo lucro, primeiramente, pouco importando se proveniente de modos tradicionais ou de modos aventureiros ou lotéricos gera condições ao descobrimento brasileiro e sua expropriação. Nesses termos, prevalece o primado do irracional, mesmo que instrumentalizado por técnicas racionais (FAORO, 2001, p. 819).

Não se pode perder de vista a compreensão das terras e das riquezas brasileiras como uma atividade mercantil, talvez uma empresa capitalista. Não um capitalismo moderno, racional e industrializado, mas, particularmente, um capitalismo político. Isto é, conforme Rubens Goyatá Campante (2003, p. 153), “[...] intervém, planeja e dirige o mais que pode a economia, tendo em vista os interesses particulares do grupo que o controla, o estamento". Promove-se, assim, em um espaço de fluência e volatização das regras do jogo. Entre o descobrimento e o fim do governo Vargas, o escorço histórico nacional vive na persistência prolongada da estrutura patrimonial, heroicamente resistente à experiência capitalista plena, com ela, as matrizes da modernidade. Nesse cenário, se opera o predomínio, no vértice da pirâmide do poder, do corpo administrativo, o 
estamento, que se burocratiza progressivamente, sobre as bases da aristocracia, primeiro pela acomodação, depois pela estrutura. Toda essa construção arquitetada pelo improviso da prática, pela conveniência no desfrute das riquezas, das concessões e dos cargos, alimenta constantemente a confusão entre os espaços públicos e os recintos privados. Logo, nestes termos, há de se visualizar um distanciamento largo das bases clássicas do Estado moderno, ou seja, a distinção público e privado.

Contudo, a adoção à brasileira dos preceitos burocráticos, isto é, o sistema burocrático implementado no Brasil, mantém pulsante notadamente o aspecto formalista do Estado. O paradigma burocrático nacional é uma adaptação para a mantença dos alicerces estamentais, especialmente no que tange ao predomínio excludente da técnica, tão somente a técnica. A teorização construída para o funcionamento do governo e da administração pública (Berufsbeamtentum), com natureza neutra, converteu-se na colônia e, posteriormente, no Império e na República como faceta do estamento político (Beamtenstand) (FAORO, 2001, p. 825).

Essa junção que dá corpo ao estamento burocrático, pela lavra de Raymundo Faoro (2001, p. 826), comanda civis e militares, dirige a economia, as finanças e a política a partir dos mesmos pressupostos, crendo que todas as atividades decorrem do Estado, estando, portanto, em sujeição a ele. Não por acaso surge a conclusão de que o Estado estamental privilegia a desigualdade e o particularismo, cujo modo de convívio pauta-se por exclusividades. Ademais, a burocracia presta-se primordialmente para a criação de cargos, que possibilitam um instrumento contundente de diferenciação social, porém que não circula de baixo para cima. Como consequência, o sistema jurídico legal e jurisprudencial " [...] costuma exprimir e veicular o poder particular e o privilégio, em detrimento da universalidade e da igualdade formal-legal" (CAMPANTE, 2003, p. 153).

Com isso, o "[...] chefe governa o estamento e a máquina que regula as relações sociais, a ela vinculadas” (FAORO, 2001, p. 827). O império imposto, cujo predomínio e dirigismo parte da apreciação dos interesses do Estado, capaz de conduzir e condicionar a Sociedade, legítimo produtor de normas e, futuramente das Constituições, cria textos semânti$\cos$ dissociados da facticidade nacional. Infelizmente, não se perdeu esta 
conotação política. Aos olhos do Estado, em linhas gerais, os problemas práticos se resolvem facilmente com normas gerais e abstratas, aprovadas e publicadas instantaneamente (STAFFEN, 2015, p. 67). A política que prevalece é a política do estamento burocrático, superior e autônoma. Não por acaso, presencie-se, ainda na atualidade, "“" [...] o único detentor impõe à comunidade sua decisão política fundamental, isto é, 'dita-a' aos destinatários do poder.” (FAORO, 2001, p. 829). A razão existencial no estamento funde-se na desigualdade edificada nas diferenciações pessoais, no exclusivismo social e na ostentação da tradição e do consumo (CAMPANTE, 2003, p. 162). Para tanto:

O estamento burocrático desenvolve padrões típicos de conduta ante a mudança interna e no ajustamento à ordem internacional. Gravitando em órbita própria não atrai, para fundir-se, o elemento de baixo, vindo de todas as classes. Em lugar de integrar, comanda; não conduz, mas governa. Incorpora as gerações necessárias ao seu serviço, valorizando a pedagógica e autoritariamente as reservas para seus quadros, cooptando-os, com a marca de seu cunho tradicional. O brasileiro que se distingue há de ter prestado sua colaboração ao aparelhamento estatal, não há empresa particular, no êxito dos negócios, na contribuição à cultura, mas numa ética confuciana do bom servidor, com carreira administrativa e curriculum vitae aprovado de cima para baixo. (FAORO, 2001, p. 831-832)

O Estado, por seu turno, mantém o povo em sua constante dependência e letargia controlada. Como consequência, apropriando-se de discurso de Joaquim Nabuco, o paradigma brasileiro de Estado é uma construção no vácuo, cujas bases são teses, não fatos; o material, ideias, e não indivíduos; a situação, o mundo, e não o país; os habitantes, as futuras gerações, e não as gerações presentes (FAORO, 2001). Há de se ressaltar que a construção do Estado brasileiro, que não se coaduna perfeitamente com a modernidade, que transita em caracteres confusos e mistos, mas que se conserva fiel aos estamentos, persiste na alimentação de uma complexa máquina uniformizadora e centralizadora no âmbito nacional. Afastando, destarte, cada vez mais o elemento humano, valendo-se do modelo de soberania absoluta, manipulando o texto constitucional e a atividade 
jurisdicional por constantes reformas para, ao final e ao cabo, subverter a burocracia pela técnica.

A junção de todos os elementos em um Estado de Modernidade tardia, de complexas e crônicas exclusões sociais, faz com que a percepção sobre corrupção esteja incrustada na existência da burocracia. Nessa senda, a noção de burocracia advinda de Max Weber, converte-se em instrumento para sustentação de modelos de corrupção sistêmica. Não por acaso, a máxima de que burocracia e corrupção, no Brasil, conformam um mercado de favores e, portanto, a redução de burocracia propicia um cenário de possibilidades reduzidas de corrupção (EXCESSO..., 2020).

\section{Modelo Brasileiro Anticorrupção e Vertentes Normativas Transnacionais}

A autonomia legislativa nacional em questões políticas, sociais, econômicas e também jurídicas é cada vez mais limitada pelas interdependências políticas, econômicas e de governance entre os Estados e a regulamentação a nível global. Isso se tornou particularmente saliente desde os episódios políticos, econômicos e sociais dos últimos 30 anos. $\mathrm{O}$ declínio da autonomia nacional, vista em alguns momentos como o "fim do Estado", deu origem a pressões políticas, institucionais e legais sobre a produção normativa no âmbito interno de cada Estado, com fluxos exógenos e endógenos trabalhando simultaneamente (STAFFEN, 2019).

Paralelamente, o fenômeno da globalização jurídica, a progressiva implementação de práticas de governance e a utilização de variados indicadores, rankings, índices e observatórios produziram uma combinação de autonomia política limitada a nível nacional e a tomada de decisão cada vez mais executiva sobre regimes especializados no nível transnacional, colocando em risco os fundamentos clássicos da deliberação política, da democracia e das fontes do direito, ao tempo em que a esfera nacional resta altamente porosa para demandas e exigências transnacionais/globais.

Há tempo o caso brasileiro de prevenção e combate à corrupção, associado com a promoção de práticas de transparência, é reflexo de pressões 
transnacionais que se sobrepõem às resistências e divergências internamente articuladas (STAFFEN; OLIVIERO, 2015). Os conflitos resultantes dessa tensão política, institucional, jurídica e social podem ser vistos na polarização da política nacional no todo e, consequentemente, na atividade legislativa. Como mudanças políticas significativas em nível nacional não parecem viáveis desde a atuação legislativa, conforme a percepção popular, a ação política é cada vez mais associada com atores transnacionais e sua autoridade emanada de indicadores por eles produzidos.

Se outrora, no Brasil, o combate à corrupção estava adstrito aos tipos penais consignados no Código Penal e aos atos de improbidade administrativa, na última década, aconteceu uma verdadeira virada de Copérnico para correlacionar práticas de corrupção com o combate ao terrorismo, o financiamento eleitoral, a lavagem de ativos financeiros, a narcotraficância, a inteligência financeira e rastreio de práticas bancárias e com investimentos e defesa de condutas de integridade na concorrência econômica.

Nesse sentido, ao tempo em que a ascendência substancial de indicadores e demais meios de governance preencheu espaços e realocou modelos tradicionais no âmbito internacional, essencialmente pela sua natureza especializada e comparativa; no cenário nacional, notadamente de produção legislativa, conquistou relevância por meio de expedientes acessórios aos contratos internacionais e pela descrença popular com a política e, especialmente, com os políticos.

A partir da fragilidade dos tradicionais atores nacionais, espaços de debilidade passa(ra)m a ser ocupados, notadamente após a Segunda Guerra, por interesses transnacionais constituídos através de instituições novas, de difícil caracterização à luz do glossário político-jurídico Moderno. A tradicional homogeneidade no pensamento político-jurídico, sedimentado sobre o Estado, fora perdida. Os atos de globalização do jurídico propiciam instrumentos para o estabelecimento de canais de abertura e interpenetração dos preceitos normativos exarados por múltiplos agentes de cunho público e/ou privado, que além do contributo na produção da norma, diante do poder que concentram, exercem atribuições de controle e correição, junto ou em substituição das funções burocráticas estatais. 
Exatamente pela envergadura que possui tal poder, as proposições de modelos jurídicos são essenciais para sua submissão.

Esse diagnóstico representa o exaurimento do Estado e das instituições internacionais de cunho monista-dualista (VON BOGDANDY, 2014, p. 1.005), tal qual havia previsto Philip Jessup (1956, p. 137), porém com engrenagens muito mais consistentes daquelas previstas em meados de 1950. As vertentes do Direito (nacional, internacional e global) articulam-se em múltiplos níveis, governos, administrações locais, instituições intergovernamentais, cortes ultra estatais e nacionais, networks, organismos híbridos (público-privado), organizações não-governamentais e dos próprios indivíduos.

Ademais, observa-se uma progressiva majoração de organizações privadas na tratativa de assuntos globais, com gerência regulamentadora e reguladora, nas mais diversas áreas de incidência e de competência material. Como consequência, observa-se uma mutação efetiva nas funções do Legislativo nacional. Tanto os eixos de pressão quanto as fontes normativas passaram através da globalização jurídica e do transnacionalismo por um amplo alargamento, em certa medida, incontornável e irrefreado. Opera-se uma sangria no tradicional paradigma de ordenamento jurídico. Agentes transnacionais lançam instrumentos jurídicos cogentes que incidem sobre a máquina estatal e as pessoas diretamente, no qual o devido processo legislativo é instrumentalizado, instalando um panorama complexo e ambíguo. Ambíguo em razão de proceder na produção normativa sobre bases contratualísticas, mixando público e privado na circulação de modelos jurídicos.

Com isso, a prática de produção e o uso de indicadores na governança global estão em constante ampliação e sofisticação. De um lado, atores transnacionais, como as agências de classificação de riscos; agências públicas de desenvolvimento internacional, como o Banco Mundial e as Nações Unidas; organismos governamentais de ajuda, como a Corporação do Desafio do Milênio, empresas globais e investidores; órgãos preocupados em avaliar ou fazer cumprir os padrões legais existentes, como órgãos de monitoramento de tratados de Direitos Humanos, ONGs e várias comunidades científicas ou especializadas, principalmente no 
campo da ciência política, sistematicamente utilizam e promovem métricas especializadas de comparação e desempenho (DAVIS; KINGSBURY; MERRY, 2012, p. 3).

Noutro lado, a publicação e circulação global de indicadores, rankings, índices e de afins infiltra-se também sobre temas e demandas nacionais/locais. Seja pelo afã de promover comparações, por imposições advindas de contratos de investimento e/ou pelo anseio de maior legitimidade das decisões produzidas, o uso de indicadores transnacionais/globais avança no território até então controlado pela política e pela burocracia soberana dos Estados.

Nesse sentido, a utilização de indicadores de governança, em que pese sua gênese transnacional com maior frequência e densidade condicionam expedientes nacionais desde fora; à distância, porém com sagacidade. O Controle da Corrupção e "rule of law", produzido pelo Banco Mundial; os indicadores dos Objetivos de Desenvolvimento do Milênio sob os auspícios da ONU; o Índice de Percepção de Corrupção desenvolvido pela Transparency International; o Índice de Desenvolvimento Humano (IDH) produzido pelo Programa das Nações Unidas para o Desenvolvimento (PNUD); os indicadores de Tráfico de Pessoas publicados pelo Departamento de Estado dos EUA; o ranking PISA de aproveitamento escolar confeccionado pela Organização para Cooperação ao Desenvolvimento Econômico (OCDE) e vários indicadores produzidos por consultorias especializadas em assessorar os investidores em riscos políticos, podem ser elencados como exemplos dessa nova tendência global (DAVIS; KINGSBURY; MERRY, 2012, p. 3-4).

A crescente produção e uso de indicadores na governança global tem o potencial de alterar as formas, o exercício e talvez até as distribuições de poder em certas esferas de governança global. Em linhas gerais, o uso de indicadores de governança sinaliza o grau de especialização conquistado em nível global (DARNACULLETA I GARDELLA, 2005, p. 63). Ao seu tempo, avança em sua capacidade de penetrar no exercício de políticas públicas, investimentos, processo legislativo, atuação judicial e organização social, bem como nos assuntos domésticos de cada Estado. 
Assim, a circulação e utilização de indicadores não se demarca perfeitamente entre o nacional, o internacional e o global. Seja para a avaliação dos impactos transnacionais, quanto influências nacionais, os mecanismos carecem de iluminação diversa do estadocentrismo ou monismo/ dualismo. Os mecanismos orientados pelo Direito Internacional, em igual medida, restam topograficamente confusos, haja vista a multiplicação de normatizações internacionais informais, pois muitas normas internacionais recentemente editadas não se configuram como tratados formais (PAUWELYN, 2012, p. 13). Os indicadores globais de governança, são globais em relação ao ente responsável pela sua produção e pela comparação que produzem, mas transitam nos espaços nacionais para condicionarem demandas locais sem deixarem de ser globais.

Conforme diagnostica Saskia Sassen (2015, p. 488), o momento atual da autoridade e do Direito é marcado pela justaposição de territórios e de poderes que se movem rapidamente graças ao domínio e a produção da informação. Para se evitar as chamadas "fracturas en la regulación", as políticas de regulação nacionais, buscam evitar o rótulo de descumprimento normativo, o vazio legislativo e/ou a desconformidade das normas com oferta de mecanismos alinhados com as demandas de atores nacionais e globais, de modo que o local, enquanto orientando pelo global, é ponto elementar para dar funcionamento desse (o global).

Diante desse cenário de justaposição e de penetração nos assuntos nacionais, especialmente na atividade legiferante, a invocação de indicadores de governança global necessita vir acompanhada de questionamentos para além do juízo de conveniência e oportunidade. Seguindo a proposta de Kevin Davis, Benedict Kingsbury e Sally Merry (2012, p. 4), a utilização de indicadores em processos nacionais perpassa saber: quais processos sociais envolvem a criação e o uso de indicadores?; como as condições de produção influenciam os tipos de conhecimento, mudam a natureza da definição de padrões e da tomada de decisão?; como isso afeta a distribuição do poder entre os que governam e aqueles que são governados?; qual é a natureza das respostas aos exercícios de poder por meio de indicadores, incluindo formas de contestação e tentativas de regular a produção ou uso de indicadores?. 
Considerando as particularidades de cada regime democrático nacional e seus procedimentos para a atividade legislativa e, noutro ponto, as especificidades dos indicadores de governança global, a saber: simplificação de dados brutos e do complexo social; comparação com demais padrões e entes; recorte temporal sobre dados e fatos e; a autoridade científica-técnica dos responsáveis por sua produção, necessário se faz uma filtragem na adoção e na mensuração da extensão do uso para os indicadores.

A mera validação e/ou referência aos indicadores em sede de atividade legislativa propicia o encampamento de questões políticas, institucionais e jurídicas sensíveis. Embora, tradicionalmente cada indicador receba uma nomenclatura alinhada com sua síntese de dados ou da sua pretensão de classificação, apenas isso não justifica o seu uso. Nesse sentido, há que se considerar que corrupção e transparência estão consubstanciadas na lógica da mensuração estatística.

Como consequência, o modelo desenhado no Brasil para o combate à corrupção, substancialmente, dada a crise de legitimidade política e a ampla desconfiança popular, é caudatário de atores transnacionais e de vertentes normativas que escapam das fontes normativas constitucionalmente previstas. Seja por atributos de autoridade ou pelo uso ideológico, interferências transnacionais são recorrentes em propostas legislativas, atos executivos e/ou decisões judiciais (STAFFEN, 2019, p. 172).

Todavia, em sede de gestão executiva/burocrática, o modelo brasileiro de combate à corrupção, especialmente no âmbito da Estratégia Nacional de Combate à Corrupção e à Lavagem de Dinheiro (ENCCLA), ganha tons distintos e paradoxais. Surge com distinção, visto que opta por diretivas para além da atividade legislativa e apresenta sinais de paradoxo, pois, em um contexto que clama pela minimização da burocracia, a ENCCLA induz a burocratização de múltiplos expedientes. Contudo, ambas as situações encontram convergência na utilização de vertentes de normatividade transnacionais para fundamentação das medidas adotadas. 
Burocratizar para não Corromper: o impacto de atores transnacionais nas medidas anticorrupção da estratégia nacional de combate à corrupção e à lavagem de dinheiro

\section{ENCCLA: mais burocracia, menos corrupção}

Criada em 2003, a Estratégia Nacional de Combate à Corrupção e à Lavagem de Dinheiro (ENCCLA), apresenta-se como uma rede de articulação para discussão, proposição e formulação de políticas públicas com foco nos respectivos tipos penais supracitados. Em sua composição, a ENCCLA, é integrada por órgãos dos Poderes Legislativo, Executivo e Judiciário, de nível federal, estadual e, excepcionalmente municipal. Igualmente tem posição de destaque o Ministério Público.

Conforme se extrai do site da ENCCLA, sua atuação centra-se na elaboração anual de Ações. Escolhidas as Ações, são constituídos grupos de trabalhos temáticos e com participação de entes convidados que confeccionam estudos e diagnósticos legais-normativos e de composição de bancos de dados, elaboram propostas legislativas, averiguam o estado da arte de sistemas de cadastros, indagam necessidades e promovem soluções em tecnologia da informação, buscam eficiência na geração de estatísticas e realizam eventos voltados à evolução dos temas por meio de debates (QUEM SOMOS, 2020).

Entretanto, desperta a atenção o fato de que a ENCCLA expressamente registra sua competência/função para, no cenário mundial, atender a recomendações internacionais. Assim, para os propósitos do presente estudo, a posição da ENCCLA apresenta-se como nuclear e protagonista, especialmente por constituir vias de diálogo e penetração de indicadores e vertentes normativas transnacionais no modelo brasileiro anticorrupção.

Por sua vez, a introdução da responsabilidade por atender às recomendações internacionais pela ENCCLA é construída e consolidada ao longo da sua existência. Em sua primeira década (2003-2013), a ENCCLA majoritariamente destinou suas energias e seus debates para prevenção de corrupção e lavagem de dinheiro decorrente do narcotráfico e crime organizado, de financiamento de terrorismo e, com o anúncio da realização da Copa das Confederações (2013), da Copa do Mundo FIFA (2014) e dos Jogos Olímpicos e Paraolímpicos (2016) de meios de controle de megainvestimentos. Contudo, tais nichos de atuação eram secundários frente às preocupações com o crime de corrupção tradicional, de âmbito nacional. 
Foi a partir de 2013-2014, com todos os acontecimentos da crise política nacional e com as manifestações populares inconformadas com a corrupção sistêmica creditada à classe política, que a ENCCLA encampou um novo perfil, desafiando novos horizontes. Se antes, os olhos estavam sobre condutas delitivas e antijurídicas, cambiou-se o foco para atuação executiva sobre movimentações financeiras, evolução dos padrões de transparência, integridade e accountability e, para a padronização de procedimentos burocráticos em nível transnacional, conforme análise do Relatório Compilação das Ações da ENCCLA 2010 a 2020 (2020).

De forma complementar, a ENCCLA, nos últimos seis anos, avançou em sua atuação transnacional, seja por meio de adoção de diretivas, indicadores e relatórios de atores transnacionais (Transparência Internacional, GAFI, OCDE, Comitê da Basileia, Alliance of Integrity), seja por meio de canalizar recomendações do Conselho de Segurança da ONU ou do MERCOSUL, seja pelo exercício concreto de representação nacional junto ao G20. Em comparação, no mesmo período, apenas um parlamentar legitimamente eleito foi mencionado como autor de proposta de Ação. A título de exemplificação, das 11 Ações propostas para o ano de 2020, 4 delas referenciam posições do GAFI (AÇÕES 2020, 2020), o que sinaliza a ascendência da autoridade transnacional perante instituições nacionais.

No respectivo espaço de tempo, a ENCCLA relegou em segundo plano os diálogos com o Legislativo para propostas de inovações legais para, progressivamente, sustentar sua atuação em medidas executivas que escapam do processo legislativo ordinário. Assim, sob a crença de inércia legislativa residente no senso comum, a ENCCLA reposiciona-se para interferir diretamente em órgãos burocráticos e de fiscalização, sem objetivar inovações legislativas.

No intervalo entre 2010 e 2020, das 154 Ações eleitas, executadas ou em desenvolvimento, 85 delas não resulta(ra)m em propostas legislativas. Apenas 69 Ações mencionaram explicitamente a necessidade de inovação ou mutação legislativa (RELATÓRIO COMPILAÇÃO DAS AÇÕES ENCCLA 2010 A 2020, 2020). Entretanto, das 11 Ações previstas para o exercício 2020, nenhuma delas menciona a necessidade de proposta legislativa. Conforme se observa no Gráfico 1, há significativa 
redução de propostas legislativas decorrentes das ações da ENCCLA, no período entre 2014 a 2020, em que pese a manutenção do número médio de Ações.

Gráfico 1 - Comparativo Ações ENCCLA

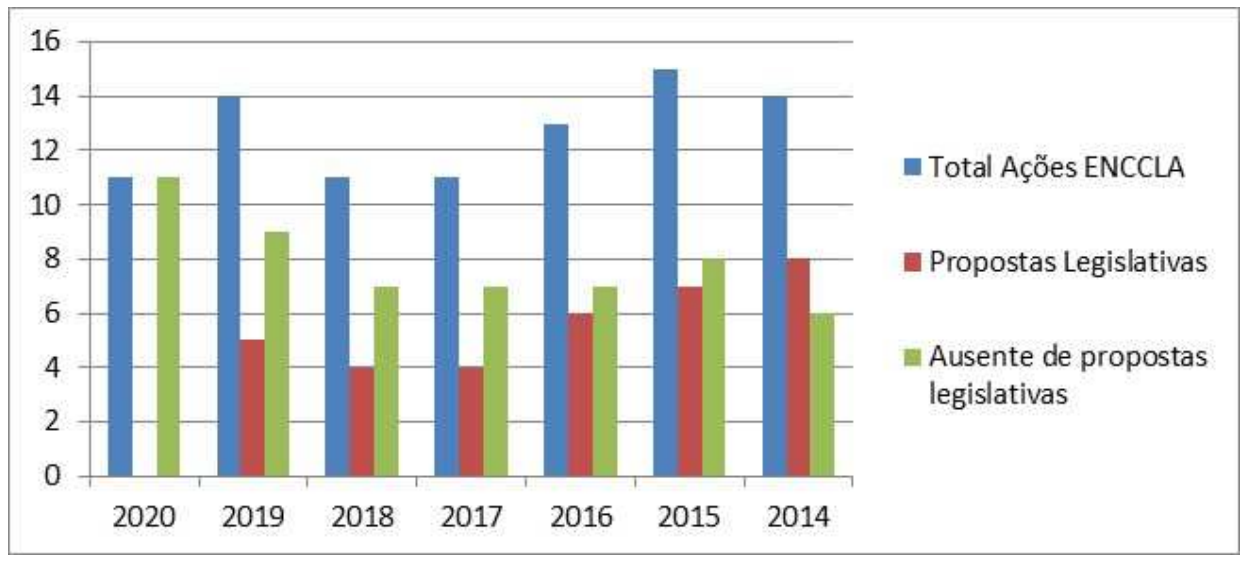

Fonte: Relatório Compilação das Ações ENCCLA 2010 a 2020 (2020)

$\mathrm{Na}$ mesma linha, para além da mudança formal de estratégias, a ENCCLA, nos últimos cinco anos tratou de cambiar substancialmente sua pauta de proposições e assuntos de intervenção. Se, na sua origem, os temas estavam associados centralmente com a criminalidade organizada, o quinquênio que nos precede demonstra uma especial atenção à padronização procedimental de expedientes de transparência, integridade, accountability com vistas ao sistema financeiro e à circulação de ativos.

No referido período, a ENCCLA, reiteradas vezes, comporta-se como lócus para instrumentalização e internalização de Recomendações do GAFI, referenciado repetidamente o compromisso do Brasil com as 40 Recomendações do GAFI, inclusive, com maior incidência se comparado com os projetos de lei em tramitação na Câmara dos Deputados no mesmo período cronológico (STAFFEN, 2019, p. 188).

Para tanto, o Plano de Prevenção de Lavagem de Dinheiro e Financiamento ao Terrorismo (PLD/FT) tornou-se ponto de partida para múltiplas e variadas estratégias de padronização, controle e denúncia de práticas envolvendo atividades financeiras. Em comum, todas as estraté- 
gias asseveram o incremento de procedimentos burocráticos, transnacionalmente espelhados, sob o argumento de redução de possibilidades de corrupção.

Não por acaso o sistema bancário nacional tenha lugar de destaque na ampliação dos procedimentos burocráticos padronizados, inclusive, desde espaços e atores transnacionais. Além das menções claras às Recomendações do GAFI, saltam aos olhos as referências à Transparência Internacional, ao Comitê da Basileia, ao FBI, à OCDE, ao Conselho de Segurança da ONU, à Alliance of Integrity e ao Mercosul, o que confirma a hipótese de procura por argumentos de autoridade externos às instituições nacionais (STAFFEN, 2018).

Ademais, das 89 Ações propostas pela ENCCLA entre 2014 e 2020, em apenas 13 Ações não há referência às instituições financeira, de ordem econômica e/ou fiscais ${ }^{3}$ no corpo de Colaboradores, destacando que desse número, duas ocorrências estão classificadas como "temas transversais", sendo que tais números apresentam declínio desde 2014 e, com completa participação de instituições financeiras, de ordem econômica e/ou fiscais em todas as Ações elencadas em 2018 e 2019.

A atuação da ENCCLA em termos de burocratização e padronização procedimental à luz de práticas transnacionais, com vistas ao sistema financeiro nacional, além dos dados já destacados, é evidente, por exemplo, na Ação n. 07/2018, aprovada em novembro de 2017, cujo teor assim prescreve: "Implementar medidas de restrição e controle do uso do dinheiro em espécie”. Da mencionada Ação derivou a Circular BCB n. 3.839/2017, a Resolução BCB n. 4.648/2018 e a Instrução Normativa RFB n. 1.761/2017. No mesmo sentido, também pode ser mencionada a Ação n. 09/2018. Ambas, no afã de combater a corrupção, incrementaram o rol de práticas burocráticas no sistema financeiro nacional.

\footnotetext{
${ }^{3}$ Foram considerados para tal levantamento os seguintes entes: Receita Federal do Brasil, Conselho Administrativo de Defesa Econômica, Comissão de Valores Mobiliários, Banco Central do Brasil, Banco do Brasil, Caixa Econômica Federal, Banco de Desenvolvimento Econômico e Social, Unidade de Inteligência Financeira, Conselho de Controle de Atividades Financeiras e Federação Brasileira dos Bancos.
} 
Em searas similares, a ENCCLA desde 2016, trata de invocar para si a tentativa de regulação de criptomoedas, moedas virtuais e similares, desafiando, assim, campos de atuação do Legislativo, do Executivo e do próprio Banco Central do Brasil, procurando convergir com modelos estrangeiros e sob recomendações do GAFI.

De forma sintética, a ENCCLA ao longo da última década reconfigura-se para assimilar novas funções que, podem ser tipificadas como destinadas, sobre o propósito de combater à corrupção, a majorar os procedimentos burocráticos nacionais, desde critérios transnacionais, elegendo como destinatário final o sistema financeiro nacional. Logo, além do paradoxo entre o senso comum, que vê na burocracia a causa da corrupção e, a técnica, que defende a burocratização como condição de combate à corrupção, há no comportamento institucional da ENCCLA outras duas situações controvertidas, a saber: primeiro, a constante referência ao combate ao terrorismo em um Estado de ausência de tais grupos; segundo, o estabelecimento de padrões burocráticos para movimentações financeiras/ bancárias em um setor majoritariamente nacional ${ }^{4}$. Em razão desse modus operandi, a atuação da ENCCLA, nesse quesito, materializa a crítica de Peter Bratsis, para quem o combate à corrupção, pode ser entendido como tática do capital transnacional para abrandamento da burocracia doméstica aos anseios transnacionais, em tempos em que a padronização global de procedimentos assegura espaços de atuação global, com maior previsibilidade de riscos e benefícios (BRATSIS, 2017, p. 23-24).

Portanto, a atuação da ENCCLA, em que pese seu mimetismo institucional e sua natureza jurídica peculiar, desafia condições mais apuradas de transparência em relação ao seu sentido e sua função, seu ser e seu dever-ser, não podendo se sintetizar na transparência como ausência de corrupção. Evidente que as Ações decorrentes da ENCCLA possuem seus méritos, principalmente em momentos de debilidade institucional, todavia, merecem contenções perante a ordem jurídico-político nacional. A presença e a pujança de vertentes normativas transnacionais não devem colocar em vassalagem os modelos constitucionais locais ou habilitar no-

\footnotetext{
${ }^{4}$ Lembrando que dos dez maiores bancos do Brasil, em ativos, apenas um é de capital estrangeiro.
} 
vos canais de colonização. O uso de indicadores, de recomendações e de ações, como ideia de Direito público necessita especificar, em sociedades democráticas, as condições e o exercício de tal poder (VON BOGDANDY; GOLDMANN, 2012, p. 53).

\section{Conclusão}

A partir dos argumentos expostos e dos dados empíricos projetados, confirma-se a tese segundo a qual o combate transnacional à corrupção tornou-se o novo normal em espaços jurídico-político-institucionais nacionais. O espaço normativo de cada Estado-Nacional não consegue se manter hermético para a influência de argumentos e atores transnacionais/ globais. Em outras palavras, as linhas de demarcação entre o local, o nacional, o internacional, o supranacional, o transnacional e o global tornou-se vulnerável, porosa e permeável perante as dinâmicas propiciadas pelas múltiplas faces da globalização e da internacionalização de fenômenos antes estanques e vistos como problemas domésticos.

Contudo, a validação de recomendações, indicadores e congêneres apenas por deferência às autoridades transnacionais ou como instrumento ideológico tende a esvaziar e comprometer o processo legislativo e, sobretudo, o resultado normativo produzido. Indicadores podem auxiliar com o Estado Democrático de Direito, mas não devem ser adotados como um argumento e/ou ideologia prêt-à-porter que a tudo justifica. Segundo Alberto Vannucci (2017), uma mobilização popular vinda de baixo pode ser considerada como a estratégia anticorrupção potencialmente mais efetiva para enfrentar o equilíbrio da corrupção sistêmica, aumentando a responsabilidade dos políticos perante as expectativas sociais quanto a uma forte integridade na esfera pública.

Em suma, esta é a crise na atuação institucional da ENCCLA, visto que, por força do mimetismo que elegeu para si, prefere pautar-se como sucursal para internalização de pautas estrangeiras, sem a devida filtragem com os ditames do Estado Democrático de Direito brasileiro. Em certa medida, haja vista os paradoxos anteriormente expostos, insufla o combate à corrupção na contramão dos anseios nacionais, substituindo, 
inclusive, prioridades, como nos casos de financiamento do terrorismo e da normatização de moedas virtuais.

No caso das padronizações procedimentais sobre movimentações financeiras e sobre o sistema financeiro nacional, as Ações da ENCCLA não apenas criam um novo conjunto de burocracias como também avançam por searas institucionais do Legislativo, do Executivo e do Banco Central do Brasil. Ao atuar assim, a ENCCLA dá nova roupagem ao combate à corrupção, pois, valendo-se desse discurso, força a abertura do setor bancário brasileiro para atores transnacionais. Com isso, a ENCCLA faz do combate à corrupção um meio para incrementar a receptividade de atores transnacionais, em que pese, peca pela ausência de opacidade desse comportamento.

Por fim, usar de procedimentos de burocratização para o combate à corrupção não se mostra condição de êxito pleno, pelo contrário, pode gerar novos ciclos de corrupção e obscuridade na gestão dos assuntos públicos, principalmente em um Estado em que a ideia de burocracia não necessariamente manteve-se fiel aos postulados de Weber. Por outro lado, não se pode combater a corrupção de modo periférico aos esteios da legalidade do Estado de Direito ou pela manipulação seletiva de discursos e práticas, ainda que elegendo argumentos de autoridade transnacionais.

Há que se considerar, no contexto de prevenção à corrupção, para além de impulsos nacionais ocorridos no Brasil, que os mecanismos de incremento burocrático induzem expedientes desterritorializados cujo propósito prioritário é garantir a previsibilidade dos atos internos de cada Estado, minimizando a opacidade para agentes estrangeiros, reduzindo custos operacionais e facilitando o trânsito transnacional de demandas comuns. Portanto, nesse quesito, as soluções propostas na sede de ENCCLA se perfilam com uma agenda transnacionalizada ascendente que penetra em fissuras da normatização nacional.

\section{Referências}

AÇÕES 2020. [2020]. Disponível em: http://enccla.camara.leg.br/acoes. Acesso em: 10 fev. 2020. 
BRATSIS, Peter. A corrupção política na era do capitalismo transnacional. Revista Crítica Marxista, Campinas, n. 44, 2017.

CAMPANTE, Rubens Goyatá. O patrimonialismo em Faoro e Weber e a sociologia brasileira. Revista Dados, Rio de Janeiro, v. 46, n. 1, 2003.

CATANIA, Alfonso. Metamorfosi del diritto: decisione e norma nell'età globale. Roma-Bari: Laterza, 2010.

CULTURA da burocracia. [2019]. Disponível em: http://www.fiesp.com. br/sietex/noticias/excesso-de-burocracia-e-o-que-mais-contribui-para-acorrupcao-diz-pesquisa/. Acesso em: 10 dez. 2019.

DARNACULLETA I GARDELLA, Maria Mercè. Autorregulación y derecho público: la autorregulación regulada. Madrid: Marcial Pons, 2005.

DAVIS, Kevin E.; KINGSBURY, Benedict; MERRY, Sally Engle. Introduction: global governance by indicator. In: DAVIS, Kevin E.; KINGSBURY, Benedict; MERRY, Sally Engle. Governance by indicators. Global power through qualification and rankings. Oxford: Oxford University Press, 2012. p. 13-37.

ESPELAND, Wendy Nelson; SAUDER, Michael. The dynamism of indicators. In: DAVIS, Kevin E.; KINGSBURY, Benedict; MERRY, Sally Engle. Governance by indicators. Global power through qualification and rankings. Oxford: Oxford University Press, 2012. p. 87-118.

EXCESSO de burocracia facilita a corrupção, diz Carmen Lucia. Correio Braziliense. [2020]. Disponível em: https://www.correiobraziliense.com. br/app/noticia/politica/2018/05/22/interna_politica,682445/excesso-deburocracia-facilita-a-corrupcao-diz-carmen-lucia.shtml. Acesso em: 22 fev. 2020.

FAORO, Raymundo. Os donos do poder: formação do patronato político brasileiro. 3. ed. Rio de Janeiro: Globo, 2001.

JESSUP, Philip. Transnational law. New Haven: Yale University Press, 1956. 
KLITGAARD, Robert. International cooperation against corruption. Finance \& Development, [S.l.], v. 35 n. 1, p. 3-6, 1998.

OLIVON, Beatriz. Para brasileiros, burocracia aumenta preços e corrupção. Revista Exame. [2018]. Disponível em: https://exame. abril.com.br/economia/para-brasileiros-burocracia-aumenta-precos-ecorrupcao/. Acesso em: 10 jan. 2018.

PAUWELYN, Joost. Informal international lawmaking: framing the concep and research questions. In: PAUWELYN, Joost; WESSEL, Ramses; WOUTERS, Jan. Informal international lawmaking. Oxford: Oxford University Press, 2012. p. 13-33.

QUEM SOMOS. ENCCLA - Estratégia Nacional de Combate à Corrupção e à Lavagem de Dinheiro. [2020]. Disponível em: http:// enccla.camara.leg.br/quem-somos. Acesso em: 25 fev. 2020.

RELATÓRIO COMPILAÇÃO DAS AÇÕES DA ENCCLA 2010 A 2020. [2020]. Disponível em: http://enccla.camara.leg.br/acoes/historicoacoes-enccla. Acesso em: $1^{\circ}$ fev. 2020.

SASSEN, Saskia. Territorio, autoridad y derechos: de los ensamblajes medievales a los ensamblajes globales. Buenos Aires: Katz, 2015.

STAFFEN, Márcio Ricardo. Estado, constituição e juizados especiais federais. Rio de Janeiro: Lumen Juris, 2015.

STAFFEN, Márcio Ricardo. Legislar por indicadores: a iniciativa legislativa brasileira anticorrupção conforme a influência de atores transnacionais. Revista de Informação Legislativa, Brasília, DF, v. 56, n. 221, p. 169-193, jan.-mar. 2019.

STAFFEN, Márcio Ricardo. Superlegality, global law and the transnational corruption combat. Revista Brasileira de Direito, [S.l.], v. 14, n. 1, p. 111-130, abr. 2018.

STAFFEN, Márcio Ricardo; OLIVIERO, Maurizio. Transparência enquanto pretensão jurídica global. A \& C - Revista de Direito Administrativo \& Constitucional, Belo Horizonte, v. 15, n. 61, p. 7191, jul.-out. 2015. 
TRANSPARÊNCIA Internacional. Índice de Percepção da Corrupção. Brasil. 2018. Disponível em: https://ipc2018.transparenciainternacional. org.br/. Acesso em: 21 dez. 2019.

TRANSPARÊNCIA Internacional. Índice de Percepção da Corrupção. Brasil. 2019. Disponível em: https://ipc2019.transparenciainternacional. org.br/. Acesso em: 23 fev. 2020.

VANNUCCI, Alberto. Challenges in the study of corruption: approaches and policy implications. Revista Brasileira de Direito, Passo Fundo, v. 13, n. 1, p. 251-281, mar. 2017.

VON BOGDANDY, Armin. Common principles for a plurality of orders: A study on public authority in the European legal area. International Journal of Constitutional Law, Oxford: v. 12, n. 4, out. 2014.

VON BOGDANDY, Armin; GOLDMANN, Mathias. Taming and framing indicators: a legal reconstruction of the OECD's Programme for International Student Assessment (PISA). In: DAVIS, Kevin E.; KINGSBURY, Benedict; MERRY, Sally Engle. Governance by indicators. Global power through qualification and rankings. Oxford: Oxford University Press, 2012. p. 59-87.

Márcio Ricardo Staffen é doutor em Direito Público Comparado pela Università degli Studi di Perugia (Itália). Doutor e Mestre em Ciência Jurídica pela Universidade do Vale do Itajaí (UNIVALI). Estágio de Pós-Doutorado em Direito Transnacional - Università degli Studi di Perugia (CAPES/PDE). Professor nos cursos de Mestrado e Doutorado em Ciência Jurídica - Universidade do Vale do Itajaí. Coordenador e Professor no Programa de Pós-Graduação Stricto Sensu em Direito - Faculdade Meridional (IMED) (2014-2018). Visiting Researcher no Max Planck Institute of Comparative Public Law and International Law (Alemanha). Doutor Honoris Causa pela Universidad Antonio Guillermo Urello (Peru). Professor Honorário da Faculdade de Direito e Ciências Sociais da Universidad Inca Garcilaso de la Vega (Peru). Advogado (OAB/SC).

E-mail:marcio.staffen@imed.edu.br 
Burocratizar para não Corromper: o impacto de atores transnacionais nas medidas anticorrupção da estratégia nacional de combate à corrupção e à lavagem de dinheiro

Endereço profissional: Rua Gal. Prestes Guimarães, n. 304, Vila Rodrigues, Passo Fundo, RS, CEP: 99070-220.

https://orcid.org/0000-0001-8979-1002 